\title{
Interference effects in short-term memory as a function of input modality and the linguistic relationship between learned lists
}

\author{
ANDREW L. WEIMAN and WILLIAM BEVAN \\ Duke University, Durham, North Carolina 27706
}

\begin{abstract}
Spoken lists of words produced greater interference, both proactive and retroactive, than did visually presented words. When the modality of presentation of the interference list differed from that of the list to be recalled, interference effects were less pronounced than when the lists were presented to the same modality. When the presentation of material shifted from vision to hearing, there was more retroaction and less proaction than when the shift occurred in the opposite direction. Finally, proactive release occurred with a shift from visual to auditory presentation, but not with the opposite shift. Degree of interference was no greater when the interference material was either semantically or phonetically related to the list to be recalled than when the two lists were totally unrelated.
\end{abstract}

The predominant number of studies of interference in short-term memory have involved a single input modality. With visually presented material, retroaction has been found to be greater for similar stimuli, either semantic or phonetic, than for dissimilar stimuli (e.g., Dale \& Gregory, 1966). However, with auditory stimuli, the outcomes are rather different. Retroaction is greater for acoustically similar stimuli (Wickelgren, 1965) but does not vary with degree of semantic similarity (Baddeley \& Dale, 1966; Kintsch \& Bushke, 1969).

Studies of interference involving two modalities have been largely confined to the phenomenon of proactive release. Release occurs with a shift from visual to auditory stimuli (Hopkins, Edwards, \& Gavelek, 1971; Murdock $\&$ Carey, 1972), although the evidence is unclear for the opposite shift. While Hopkins et al. failed to observe release, Murdock and Carey reported a small effect. There is also evidence (Murdock \& Carey, 1972) for a small retroactive release following an auditory-to-visual shift. Interference, as one might expect from the similarity principle, appears to be less pronounced when the interfering stimuli are presented to a different rather than the same modality (Murdock \& Walker, 1969).

The rationale of the present experimental exercise is simple and straightforward. It was assumed that a more definitive picture of the influence of modality shifts upon interference could be obtained if the modality of stimulus presentation and the linguistic properties of the stimulus material were systematically covaried under a carefully arranged common set of conditions.

\section{METHOD}

Design

The experimental strategy employed four groups of subjects

A. L. Weiman is now at the Department of Psychology, New York University. organized into a comprehensive design involving both betweengroup and within-group manipulations. The between-group manipulations were type of presentation mode (all stimuli to one modality vs. half to one and half to the other) and direction of shift in modality of stimulus presentation (shift from visual to auditory stimuli or vice versa). Thus one group received only visual stimuli (V-V); a second, only auditory stimuli (A-A); the third, visual followed by auditory stimuli (V-A); and the fourth, auditory followed by visual stimuli (A-V).

Two other conditions, the linguistic relationship between sets of stimuli paired in the interference paradigm and the type of interference paradigm employed on individual trials, were systematically varied within groups.

Each group of subjects received two sets of stimuli (lists of words) on each test trial. On one-fourth of the trials, the linguistic relationship between sets was semantic (the words of the second set were synonyms of those in the first); on a second one-fourth, it was phonetic (the words of the second set sounded like those of the first); and on a third one-fourth, the relationship was random (the two sets contained words that were both semantically and phonetically unrelated). The last one-fourth of the test trials constituted the control condition for assessing interference (the sequence consisted of a set of words followed by an arithmetic task in which the subject counted backward by threes from a designated three-digit number).

Both interference paradigms were included. Retroaction was tested on one half of the interference trials and proaction on the other. This was accomplished by presenting both sets of stimuli and then signaling the subject which set was to be recalled.

Subjects

A total of 128 introductory psychology students at Duke University, both male and female, served as subjects. Thirtytwo were assigned at random to each of the four experimental groups.

\section{Materials and Apparatus}

Each stimulus set consisted of five unrelated monosyllabic words. Semantically matched sets were constructed with the aid of a synonym dictionary (Webster's Dictionary of Synonyms, 1942). Phonetically matched sets were created by pairing words that rhymed. All sets consisted of words of approximately equal frequency of usage and were selected from the Kucera and Francis (1967) list. The words were ordered within each set such that the perception of a meaningful sequence would be highly unlikely. 
There were two paired sets of stimuli for each linguistic condition and two sets for the interference control. The individual words within each set were arranged for sequential presentation, the visual stimuli by means of a Kodak Carousel $860 \mathrm{H}$ projector, and the auditory stimuli by means of a Panasonic cassette tape recorder. The words within each sequence had a presentation time of $1 \mathrm{sec}$, with an interstimulus interval of $.5 \mathrm{sec}$, and a between-sets interval of $2 \mathrm{sec}$. A Grason-Stadler electronic timer was modified to control both on-times and intervals.

\section{Procedure}

Subjects were tested individually or in pairs. Each received written instructions that indicated that there would be a series of trials, each consisting of two sets of sequentially presented common words, and that the presentation modality for each set would be identified. (This was done to avoid a "startle effect" when modalities were shifted.) The instructions also explained that presentation of the number 1 following the second set signaled that recall of the first set was requested, while presentation of the number 2 designated recall of the second set.

Each subject received four randomly sequenced practice trials: one requiring recall of the first of the two-word sets, one requiring recall of the second, one in which the arithmetic task preceded the word set, and one in which it followed. These were followed by eight randomly ordered test trials: two for each linguistic condition, with one of these for each type of interference, and two counterbalanced control trials, one to test for proaction, the other for retroaction.

\section{RESULTS AND DISCUSSION}

\section{Interference in Primary Memory}

A within-subjects analysis that compared the performance level for the combined proaction experimental trials with that for their controls revealed significantly poorer performance during the interference condition $[F(1,124)=40.15, p<.001]$. This proaction effect proved to be weaker (see Figure 1) than the retroaction, which was also observed $[\mathrm{F}(1,124)=12.05, \mathrm{p}<.001]$, an outcome consistent with the long-known results for secondary memory (McGeogh \& Underwood, 1943; Underwood, 1945; Wickelgren, 1966).

If one accepts the Tulving and Colotla (1970) contention that a stimulus process may be assumed to be in primary memory if no more than seven stimuli (words) intervene between its presentation and recall, then the present data indicate the occurrence of proaction in primary memory and contradict the conclusion of Craik and Birtwistle (1971). Since the latter authors interpret their failure to find proaction in primary memory to indicate the dual process nature of memory, the present data suggest that support for this conceptualization must now be sought elsewhere. Indeed, it should be emphasized that in the present experiment proaction occurred with a retention interval of only $2 \mathrm{sec}$, which is within the 10- to 60-sec limit generally identified with short-term memory.

\section{Interference as a Function of Input Modality}

Figure 2 presents level of performance for the two single-modality conditions and the two mixed-modality conditions. Inspection indicates more interference when

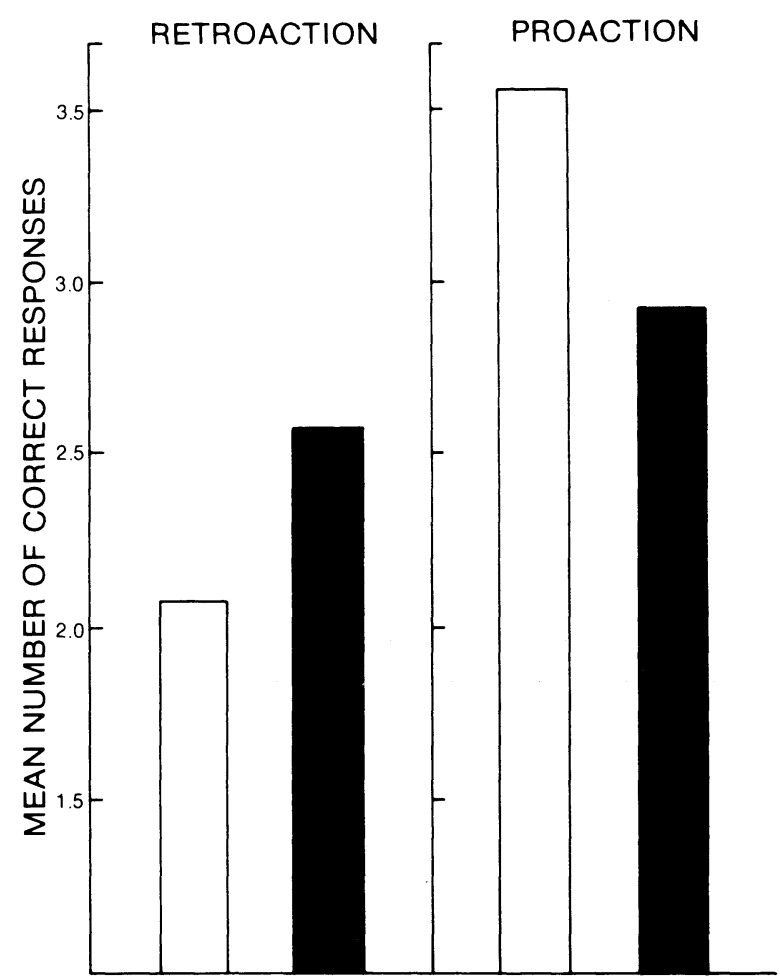

INTERFERENCE SEQUENCE

Figure 1. Level of recall in short-term memory for both retroactive and proactive experimental paradigms. The white represents the average of combined control conditions; the black represents the average of the combined experimental conditions.

the interfering material was presented to the same modality than when there was a shift in modalities. This was confirmed by statistical test $[\mathrm{F}(1,124)=6.43$, $\mathrm{p}<.05$ ] and is consistent with the reports of Murdock and Carey (1972) and Murdock and Walker (1969). One possible reason for these results is that there is less confusion between successive sets of stimuli when modality shifts. Further comparison indicated that direction of shift had no effect overall on recall, nor were there any differences in level of recall between vision and audition when proaction and retroaction were considered together.

There was, however, a significant Modality by Sequence interaction $[F(3,124)=15.50, p<.001]$, indicating that when successive lists were presented visually, retroaction was less than when they were spoken $[F(1,124)=10.47, p<.01]$. On the other hand, there was no significant difference between modalities in amount of proactive interference. Under the mixed-modality conditions, auditory input produced greater interference than did visual input, irrespective of whether that interference was proactive or retroactive $[\mathrm{F}(1,24)=31.73, \mathrm{p}<.001]$. This agrees with the results of Murdock and Walker (1969). Finally, proactive release occurred with the shift from visual to 


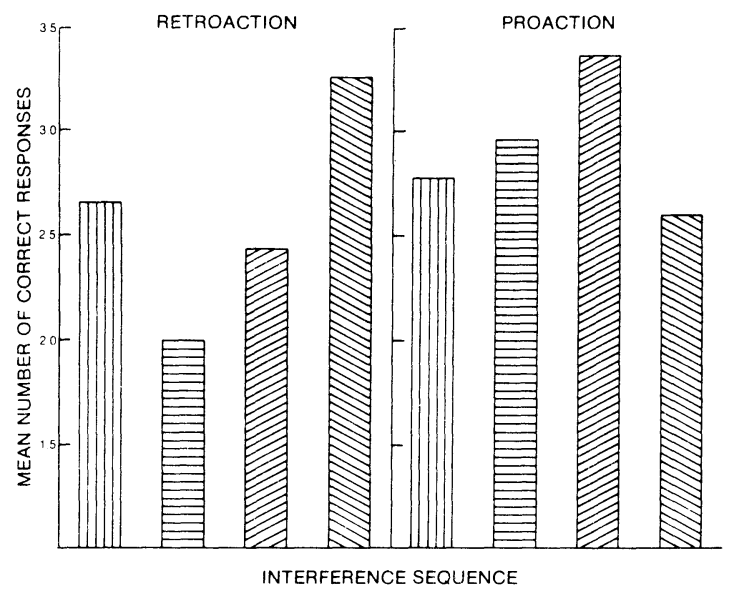

Figure 2. Levels of interference under both single-modality and mixed-modality conditions. The vertically hatched bars represent the V-V sequence; the horizontally hatched, the A-A sequence; the diagonally hatched rising rightward, the V-A sequence; the diagonally hatched dropping rightward, the A-V sequence.

auditory presentation but not with the opposite shift, a finding in line with Hopkins et al. (1971) but not with Murdock and Carey (1972), who found a small effect with an auditory-to-visual shift.

\section{Interlist Relationships in Recall}

There were no significant differences among the several types of interlist relationships. Neither the semantically nor the phonetically similar interference sets had any greater effect upon recall than did the linguistically unrelated set. Furthermore, the Modality by Interlist Relationship interaction lacked significance, indicating that modality did not differentially influence interference for any of the various kinds of stimulus material used. Finally, sequence of presentation failed to interact with interlist relationship. Thus the results were the same for both proaction and retroaction.

Why these results differ from the earlier findings of Dale and Gregory (1966) and Wickelgren (1965) is unclear. Differences in list length or in the degree of similarity between lists could conceivably account for the divergent findings.

\section{REFERENCES}

Baddeley, A. D., \& Dale, H. C. A. The effect of semantic similarity on retroactive interference in long-term and shortterm memory. Journal of Verbal Learning and Verbal Behavior, $1966,5,417-420$.

Craik, F. I. M., \& Birtwistle, J. Proactive inhibition in free recall. Journal of Experimental Psychology, 1971, 91, 120-123.

DALE, H. C. A., \& GREGORY, M. Evidence of semantic coding in short-term memory. Psychonomic Science, 1966, 5, 75-76.

Hopkins, R. H., Edwards, R. E., \& Gavelek, J. R. Presentation modality as an encoding variable in short-term memory. Journal of Experimental Psychology, 1971, 90, 319-325.

KintsCh, W., \& Bushкe, H. Homophones and synonyms in short-term memory. Journal of Experimental Psychology, 1969, 80, 403-407.

Kučera, H., \& Francis, W. N. Computational analysis of present-day American English. Providence, R.I: Brown University Press, 1970.

McGeogh, J. A., \& Underwood, B. J. Tests of the two-factor theory of retroactive inhibition. Journal of Experimental Psychology, 1943, 32, 1-17.

Murdock, B. B., \& CAREY, S. T. Release from interference in single-trial free recall. Journal of Verbal Learning and Verbal Behavior, 1972, 11, 398-402.

Murdock, B. B., \& W WLKER, K. D. Modality effects in free recall. Journal of Verbal Learning and Verbal Behavior, 1969, 8, 665-676.

Tulving, E., \& Colotla, V. A. Free recall of trilingual lists. Cognitive Psychology, 1970, 1, 86-98.

UNDERWOOD, B. J. The effect of successive interpolations on retroactive and proactive inhibition. Psychological Monographs, 1945, 59(Whole No. 273).

Webster's dictionary of synonyms. Springfield, Mass: Merriam, 1942.

Wickelgren, W. A. Acoustic similarity and retroactive interference in short-term memory. Journal of Verbal Learning and Verbal Behavior, 1965, 4, 53-61.

Wickelgren, W. A. Phonemic similarity and interference in short-term memory for single letters. Journal of Experimental Psychology, 1966, 71, 396-404.

(Received for publication August 28, 1979.) 